\title{
Older-instar larvae of Pseudopsinae (Coleoptera: Staphylinidae): morphological description of three genera and phylogenetic placement of the subfamily
}

\author{
VASILY V. GREBENNIKOV \\ Department of Entomology, Institut für Spezielle Zoologie und Evolutionsbiologie mit Phyletischem Museum, \\ Friedrich-Schiller-Universität Jena, Erbertstraße 1, 07743 Jena, Germany, \\ and Centre for Plant Quarantine Pests, Canadian Food Inspection Agency, Room 4125, K.W.Neatby Bldg., 960 Carling Avenue, \\ Ottawa, Ontario K1A 0C6, Canada; e-mail: v_grebennikov@mail.ru
}

Key words. Coleoptera, Staphylinidae, Pseudopsinae, Pseudopsis, Nanobius, Zalobius, larva, immature stages, description, morphology, phylogeny

\begin{abstract}
Larvae of three genera representing the staphylinid subfamily Pseudopsinae are described for the first time and illustrated with 33 morphological drawings: Pseudopsis Newman, Zalobius LeConte and Nanobius Herman. Thirty-six characters (mainly of larval morphology) were scored for representatives of six staphylinid subfamilies and a phylogenetic analysis was carried out. The monophyly of the subfamily Pseudopsinae is supported by the presence of a short oblique ridge on ventral side of larval head capsule laterad of maxillary foramina. The monophyly of each of the subfamilies Paederinae and Staphylininae is discussed based on the characters of the immature stages. The subfamily Pseudopsinae is confirmed to be a sister-group of the subfamilies Paederinae + Staphylininae on the basis of six larval synapomorphies. The latter clade is confirmed to be monophyletic on the basis of five larval synapomorphies. A larval identification key to the studied Pseudopsinae genera is provided.
\end{abstract}

\section{INTRODUCTION}

The subfamily Pseudopsinae, as defined by Newton (1982), comprises four genera. The genus Pseudopsis Newman, 1834 is by far the largest among them and presently includes 51 species distributed in the Holarctic, Neotropical, and north Oriental Regions, as well as in Chile, southern Argentina and in New Zealand (Herman, 2001; Newton \& Thayer, 2003). The remaining three genera, Zalobius LeConte, 1874, Asemobius Horn, 1895 and Nanobius Herman, 1977 comprise two, one and one species respectively, and are all restricted to the western part of the Nearctic Region (Newton \& Thayer, 2003). Adult beetles representing all four genera of Pseudopsinae are depicted in Figs 35-38.

The history of the taxonomic placement of the taxa constituting Pseudopsinae was summarized by Newton (1982). The most recent phylogenetic hypothesis of Pseudopsinae implies that the group is a monophylum and it is supported by a number of autapomorphic features of adults. Twelve autapomorphies were listed (Newton, 1982; see also Herman, 1975, 1977 and Thayer, 2005), of which the most characteristic is the unique (within the family) presence of the lateral stridulatory files on tergum IX (Newton, 1982). Larval autapomorphies of the subfamily are unknown. In contrast to this the presently widely accepted hypothesis of the sister-group relationship between Pseudopsinae and a clade consisting of Paederinae and Staphylininae is almost exclusively explained on the basis of larval characters, particularly by the unique (within the family) closure of the maxillary grooves on the ventral surface of the head capsule (Thayer, 2005). The sister group of the assemblage containing these three subfamilies is believed to be either
Leptotyphlinae or Euaesthetinae (Thayer, 2005; the monophyly of the latter group is uncertain).

Information on the larval morphology of the members of Pseudopsinae became available since 1990, when the genera Pseudopsis and Nanobius were included into the larval key of the soil-dwelling North American Staphylinidae (Newton, 1990). Some additional information on the states of 33 larval characters of the genus Pseudopsis can be obtained from the data matrix prepared in order to clarify the position of some taxa within the clade of Paederinae + Staphylininae (Solodovnikov \& Newton, 2005). Characters of the larval morphology of Pseudopsinae were shortly discussed in the summary of the presently best corroborated higher-level phylogenetic hypotheses within Staphylinidae (Thayer, 2005). The only published larval illustration of Pseudopsinae is the ventral view of the prothorax of Pseudopsis subulata Herman, 1975 showing the shape of the cervicosternum (Solodovnikov \& Newton, 2005).

There are two aims of the present study. The first is to describe and extensively illustrate external morphology of the mature larvae of three genera of Pseudopsinae: Pseudopsis, Nanobius and Zalobius and to provide a key to, and diagnoses of, the studied genera and the subfamily. The second aim is to perform a phylogenetic analysis with the purpose (i) to find possible larval autapomorphies of the subfamily, (ii) to re-address critically the sister-group relationship between Pseudopsinae and Paederinae + Staphylininae and (iii) to outline the new and previously cited larval apomorphies for and within the clade comprising these three subfamilies. 
TABLE 1. Data matrix for the phylogenetic analysis of Pseudopsinae and related Staphylinidae larvae.

$\begin{array}{lllllllll} & 0 & 5 & 10 & 15 & 20 & 25 & 30 & 35 \\ \text { Oxyporus } & 00000 & 0000- & -0-00 & 00000 & 0000- & 00002 & 00100 & 0 \\ \text { Megalopinus } & 00000 & 10111 & -0-00 & 01000 & 00000 & 00100 & 0000 ? & ? \\ \text { Euaesthetus } & 00100 & 01111 & 00112 & 01010 & 00100 & 00011 & 0001 ? & ? \\ \text { Pseudopsis } & 00111 & 11111 & 01010 & 11011 & 11110 & 01012 & 0011 ? & ? \\ \text { Zalobius } & 10111 & 1110- & 01110 & 11011 & 11110 & 00012 & 0010 ? & ? \\ \text { Nanobius } & 10111 & 11111 & 01010 & 11011 & 11110 & 01012 & 0010 ? & ? \\ \text { Pinophilus } & 01111 & 11110 & 10012 & 11111 & 11111 & 00012 & 11001 & 0 \\ \text { Arrowinus } & 00111 & 11110 & 10111 & 01111 & 11110 & 11112 & 11100 & 1 \\ \text { Xanthopygus } & 10111 & 11110 & 10111 & 01111 & 11110 & 11112 & 11200 & 1 \\ \text { Platydracus } & 10111 & 11110 & 10111 & 01111 & 11110 & 11112 & 11200 & 1\end{array}$

\section{MATERIAL AND METHODS}

Specimen identification, preparation, illustrations, and terminology

Larvae of Pseudopsinae were collected in the field, identified by $\mathrm{A}$. Newton and $\mathrm{M}$. Thayer, and stored in 70\% ethanol at the Field Museum of Natural History (FMNH), Chicago. I consider the identification of these larvae correct based on the following reasons: (i) at least some larvae were collected together with the adult beetles and all came from within the range of the respective species; (ii) these larvae cannot be readily assigned to any subfamily of Staphylinidae, are rather similar to those of Staphylininae and Paederinae and yet differ significantly from them and (iii) full-grown larvae approximately correspond in size to the pseudopsine adult beetles. Larvae (five specimens in total, for their collection information see under the treatment for each species) were borrowed from FMNH, macerated in about $5 \%$ hot solution of $\mathrm{KOH}$, passed through the increasing water solution of iso-propanol and mounted on microscope slides in Euparal medium. Details of larval morphology were observed with a compound microscope under 50-900× magnification, while the morphological drawings were made with the aid of a camera-lucida. Pencil drawings were scanned as Windows Metafiles (.wmf) and arranged on plates in the graphical editor CorelDraw. Photos of adult beetles (Figs 35-38) were taken using Nikon DXM1200F digital camera mounted on Nikon SMZ1500 dissecting microscope. A few images of one specimen were taken with different focal depth. These images were automatically combined into a single sharp image using CombineZ (Hadley, 2004) and arranged on plate. Morphological terms are those explained in Lawrence (1991) with some subsequent modifications (Solodovnikov \& Newton, 2005). Only older-instar larvae were available for the study. Abbreviation "MPT" means "the most parsimonious tree or trees".

\section{Choice of ingroup and outgroup taxa}

The ingroup was chosen to include three available representatives of the subfamily Pseudopsinae, as well as four genera representing the subfamilies Paederinae and Staphylininae (the taxa believed to be most closely related to Pseudopsinae; see Solodovnikov \& Newton, 2005, Thayer, 2005). The choice of the outgroup taxa was less straightforward, since the phylogenetic scheme within the Staphylininae Group of subfamilies is not fully resolved (Thayer, 2005). Therefore, members of Oxyporinae (represented by Oxyporus rufipennis LeConte, 1863), Megalopsidiinae (represented by Megalopinus sp.) and Euaesthetinae (represented by Euaesthetus sp.) were used as multiple outgroups.

\section{Phylogenetic analysis}

Reconstruction of the phylogeny was performed based on a matrix comprising 36 larval characters (Table 1, characters 1,7 , $16,24,29,34$ and 35 were excluded from the analysis), compiled in Winclada version 1.00 .08 (Nixon, 2002), and then spawned in Hennig86 (Farris, 1988) using the exhaustive search option (implicit enumeration; i.e. ${ }^{*}$ ) to search for the shortest trees. All characters were treated as equally weighted and unordered (for multistate characters). A single shortest tree 43 steps long was obtained, with consistency index 0.72 and retention index 0.80 (Fig. 34). Character state distributions were examined with WINCLADA (Nixon, 2002) and the selected trees were exported as Corel Metafiles and edited in CorelDraw.

\section{SUBFAMILY PSEUDOPSINAE}

\section{Larval description and diagnosis (older instars)}

General features. Larvae campodeifom (resembling larvae of Paederinae and Staphylininae); with all setae of simple type (Figs 1, 19, Pseudopsis), or with some setae on thorax and body slightly irregularly frayed (Fig. 24, Nanobius) to most setae markedly frayed (Figs 5, 26, Zalobius); without long trichobothria; with dorsal surface lightly pigmented, sclerotized and covered with toothed microsculpture; relatively large pore-like structures (possible gland openings) located on each side of epicranium lateral of frontal arms (Figs 1, 3, 5), on each protergum (Figs 19, 24, 26) and near anterolateral corners of meso(Figs 19, 24, 26), metasternum, and terga I-IX (Figs 27, 32, 33). Head. Prognathous and protracted; with distinct neck constriction (Figs 1-6); lateral margins almost straight; narrower than thorax; with epicranial stem longer than half length of head capsule; with frontal arms lyriform; gula absent, gular sutures completely fused; with ventral ecdysial line present, only shortly branching anteriorly and reaching posterior tentorial pits (Figs 2, 4, Pseudopsis, Nanobius) or branching, extending anterolaterally in two divergent lines (Fig. 6, Zalobius); ventral surface of head capsule with short oblique slightly curved ridge latero-basally of closed maxillary foramina (Figs 2, 4, 6); tentorial bridge long and thread-like. Six clearly separated stemmata present on each side of head (in Pseudopsis apparently only four closely aggregated stemmata present). Antennae. 3-segmented; penultimate segment with parallel-sided and anteriorly located sensorial appendage (Figs 16-18), three solenidia and three long setae; last segment with four solenidia at apex and three long setae. Mouthparts. Labrum completely fused to clypeus forming anteriorly toothed nasale (Figs 2, 4, 6, 7-9). Mandibles symmetrical, narrow and falcate, lacking preapical teeth or serration (Figs 1-6). Articulating area of ventral mouthparts absent (Figs 2, 4, 6), maxillae separated from labium and base of cardo completely enclosed. Cardo elongate, without internal ridge (Figs 10, 12, 14). 

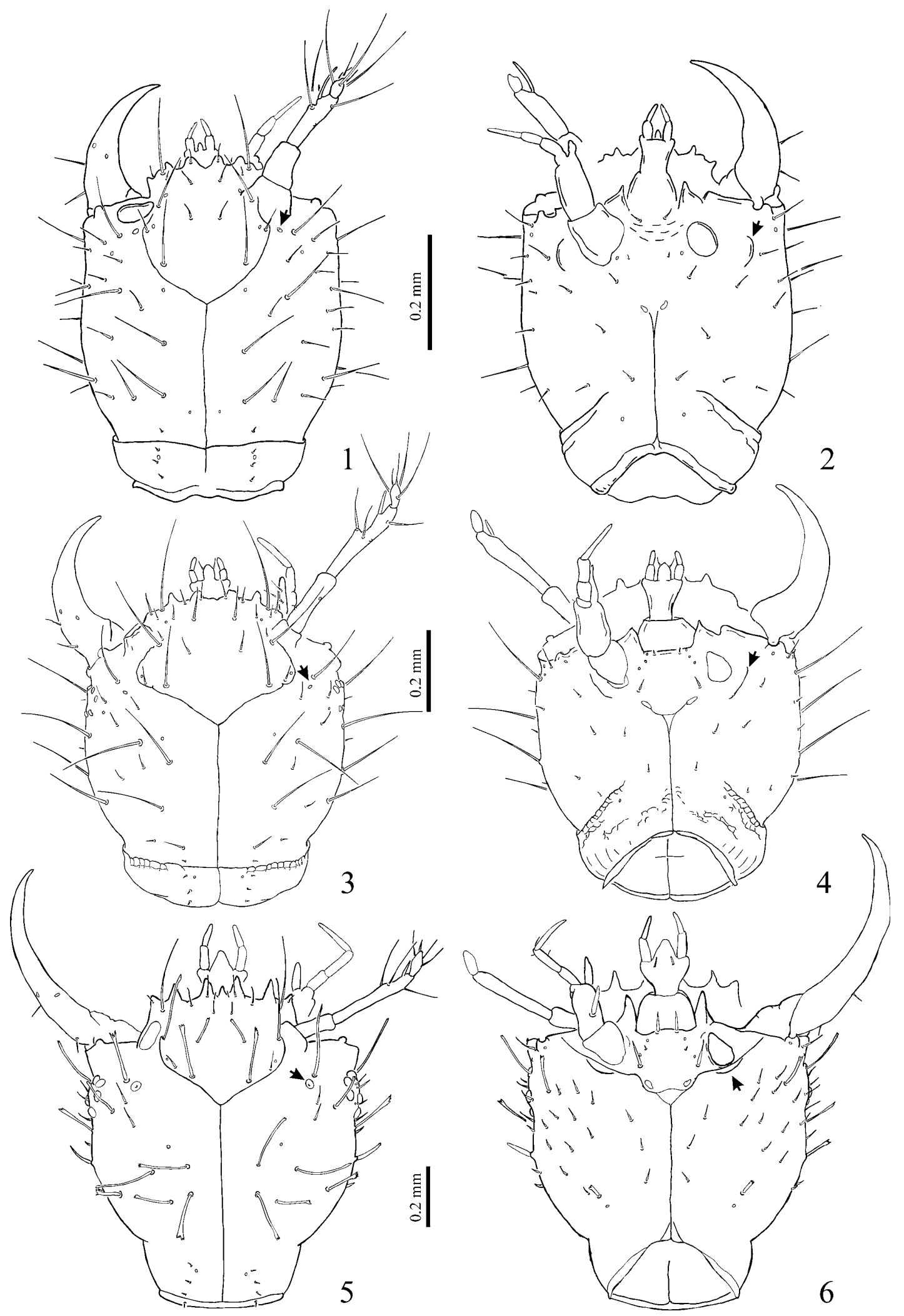

Figs 1-6. Larvae of Pseudopsinae (Coleoptera: Staphylinidae), details. 1, 2 - Pseudopsis montoraria, head dorsal (Fig. 1) and ventral (Fig. 2); 3, 4 - Nanobius serricollis, head dorsal (Fig. 3) and ventral (Fig. 4); 5, 6-Zalobius spinicollis, head dorsal (Fig. 5) and ventral (Fig. 6). Arrows show large pore-like structures on epicranium (Figs 1, 3, 5) and short oblique ventral ridges (character 11, Figs 2, 4, 6). 


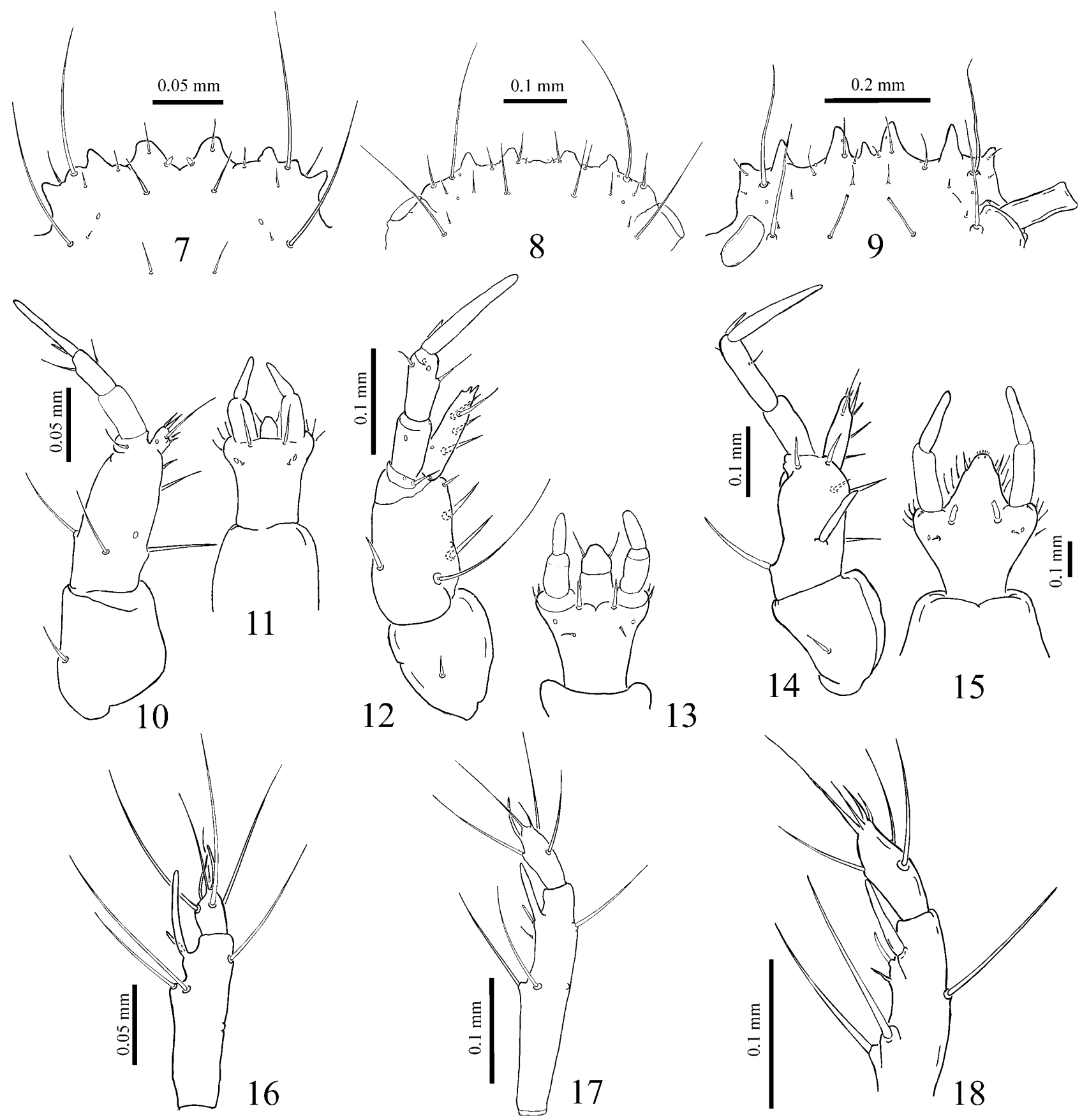

Figs 7-18. Larvae of Pseudopsinae (Coleoptera: Staphylinidae), details. 7-9 - nasale, dorsal; 10-15 - right maxilla and prementum, ventral; 16-18 - second and third antennomere of right antenna, dorsal. 7, 10, 11, 16-Pseudopsis montoraria; 8, 12, 13, 17Nanobius serricollis; 9, 14, 15, 18 - Zalobius spinicollis.

Stipes longer than wide, with articulated digitiform setose mala, with palpifer and three palpomeres (Figs 10, 12, 14). Ligula present (Figs 11, 13, 15), narrowing apically; palpi of two palpomeres. Thorax and legs. Thoracic terga with (Figs 19, 24, Pseudopsis, Nanobius) or without (Fig. 26, Zalobius) transverse carina posteriorly. Cervicosternum transverse, not protruding posteriorly (Figs 20, 25). Claws with two simple setae (Figs 21-23). Tarsus without comb or bifid setae (Figs 21, 22). Abdomen. Terga and sterna without transverse carina near anterior margin (Figs 27-30); with undivided tergal and sternal sclerites, with two pairs of laterotergites on segments
I-VIII (Figs 28, 30); with spiracles placed on membrane just outside terga. Paired urogomphi present on tergum IX (Figs 31-33), 1- (Pseudopsis) or 2-segmented (Nanobius, Zalobius). Abdominal segment X cylindrical (Figs 31-33).

KEY TO THE SUBFAMILIES STAPHYLININAE,

PAEDERINAE, PSEUDOPSINAE AND TO THE

PSEUDOPSINAE GENERA PSEUDOPSIS, NANOBIUS AND ZALOBIUS BASED ON LARVAE

[partly based on Kasule (1970) and Newton (1990)] 


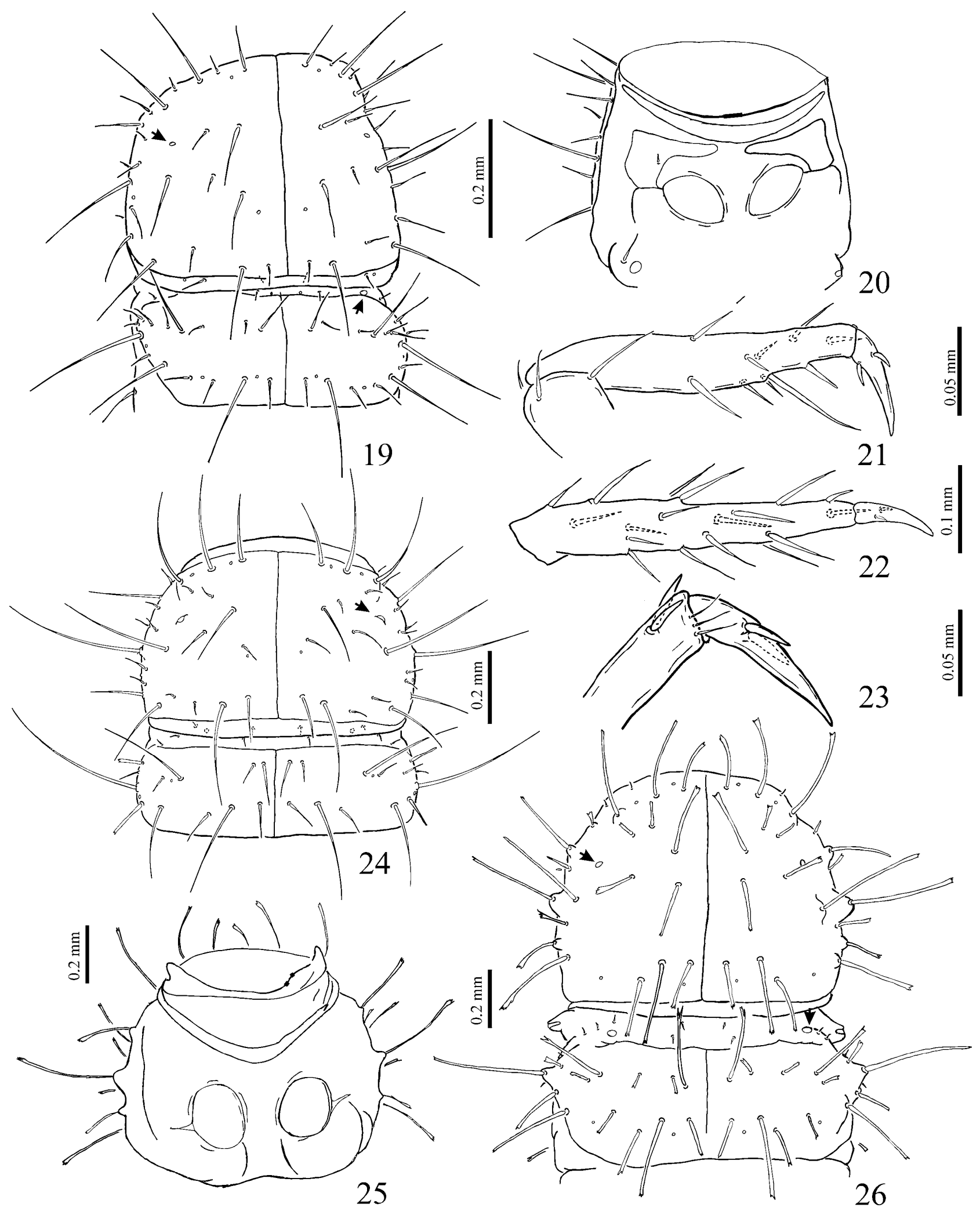

Figs 19-26. Larvae of Pseudopsinae (Coleoptera: Staphylinidae), details. 19, 24, 26 - pro- and mesothorax, dorsal; 20, 25 prothotax, ventral (legs omitted); 21, 22, 23 - left tarsus and claw, anterior. 19-21 - Pseudopsis montoraria; 22, 24 - Nanobius serricollis; 23, 25, 26 - Zalobius spinicollis. Arrows show large pore-like structures on thoracic terga.

1 Head capsule always with a well-developed neck (Figs 1-6) often delimited by nuchal carina (Figs 1-4); coronal stem of dorsal epicranial line longer than half length of head capsule (Figs 1, 3, 5); mandibles falcate, sickle-shaped, without preapical tooth (Figs 1-6); labrum fused with clypeus forming toothed nasale (Figs 1, 3, 5, 7-9); maxillary articulating area absent, maxillary attachment to head capsule completely closed anteriorly and mesally, mentum fused 


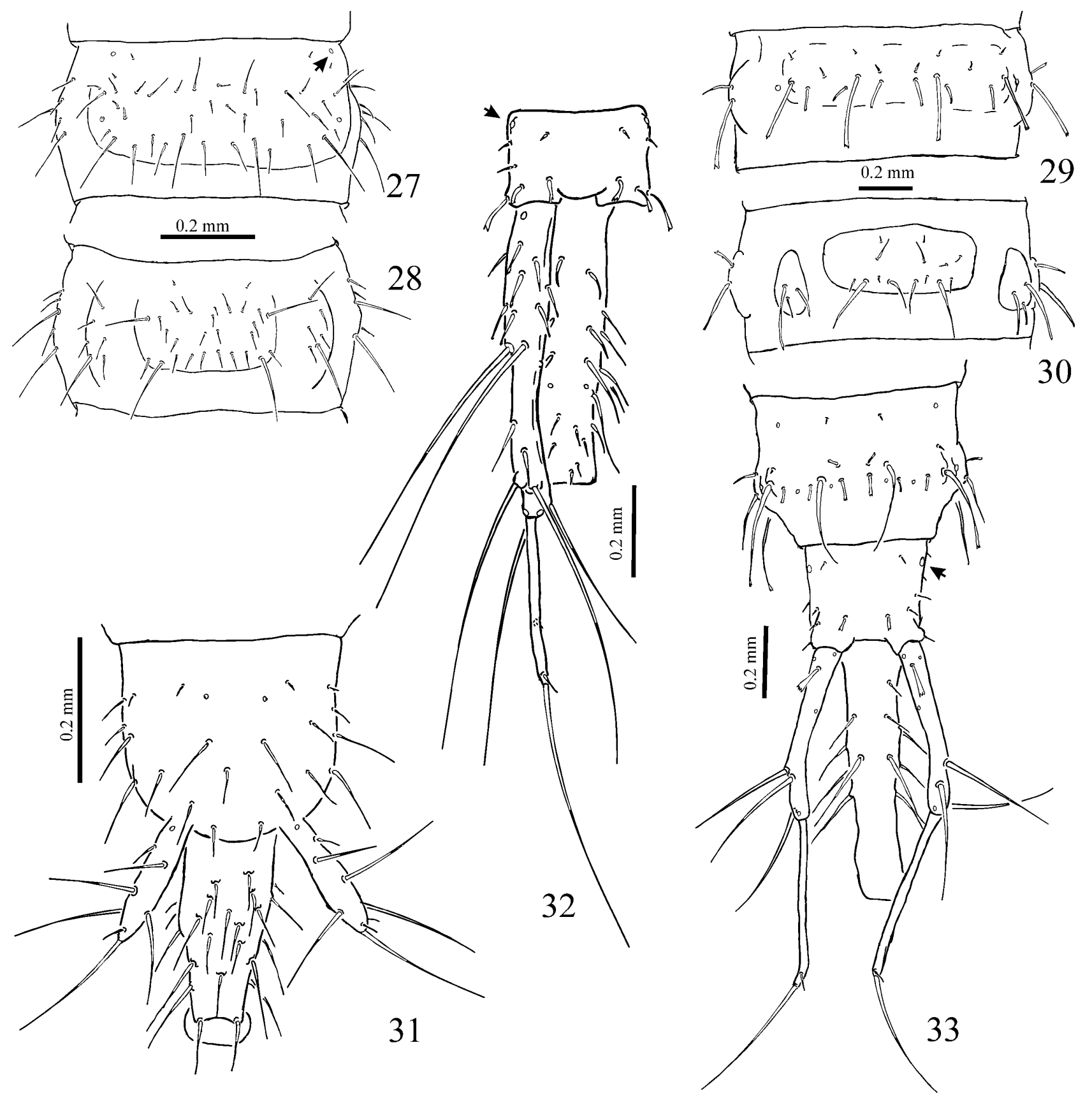

Figs 27-33. Larvae of Pseudopsinae (Coleoptera: Staphylinidae), details. 26-30 - abdominal segments VI, dorsal (Figs 27, 29) and ventral (Figs 28, 30); 31, 32 - abdominal segments IX and X (right urogomphus omitted on Fig. 32); 32 - abdominal segments VIII-X. 27, 28, 31 - Pseudopsis montoraria; 32 - Nanobius serricollis; 29, 30, 33 - Zalobius spinicollis. Arrows show large porelike structures on abdominal terga.

with head capsule (Figs 2, 4, 6); mala digitiform and articulated to stipes (Figs 10, 12, 14); cardo rather elongate, without internal ridge (Figs 10, 12, 14); abdominal segments I-VIII with two laterosclerites on each side (Figs 28, 30). . . . (Staphylininae, Paederinae or Pseudopsinae) (NB. Larvae of some Euaesthetinae are remarkably similar in some key characters to those of Staphylininae, Paederinae and Pseudopsinae. The larvae of the former subfamily differ, however, by maxillary foramina open mesally, by the presence of only one laterosclerite on each side of abdominal segments I-VIII, and by always 1-segmented and short urogomphi)
- Head capsule without a well-developed neck and usually without nuchal carina; coronal stem of dorsal epicranial line shorter, maximally half as long as head capsule; mandibles rarely falcate, and usually with preapical tooth; labrum usually free and not fused with clypeus forming nasale; maxillary articulating area present at least mesally; mala variously shaped and broadly attached to stipes; mentum usually free; cardo rather transverse or triangular, usually with internal ridge; abdominal segments II-VIII usually with one or without laterosclerites on each side.... other Staphylinidae 


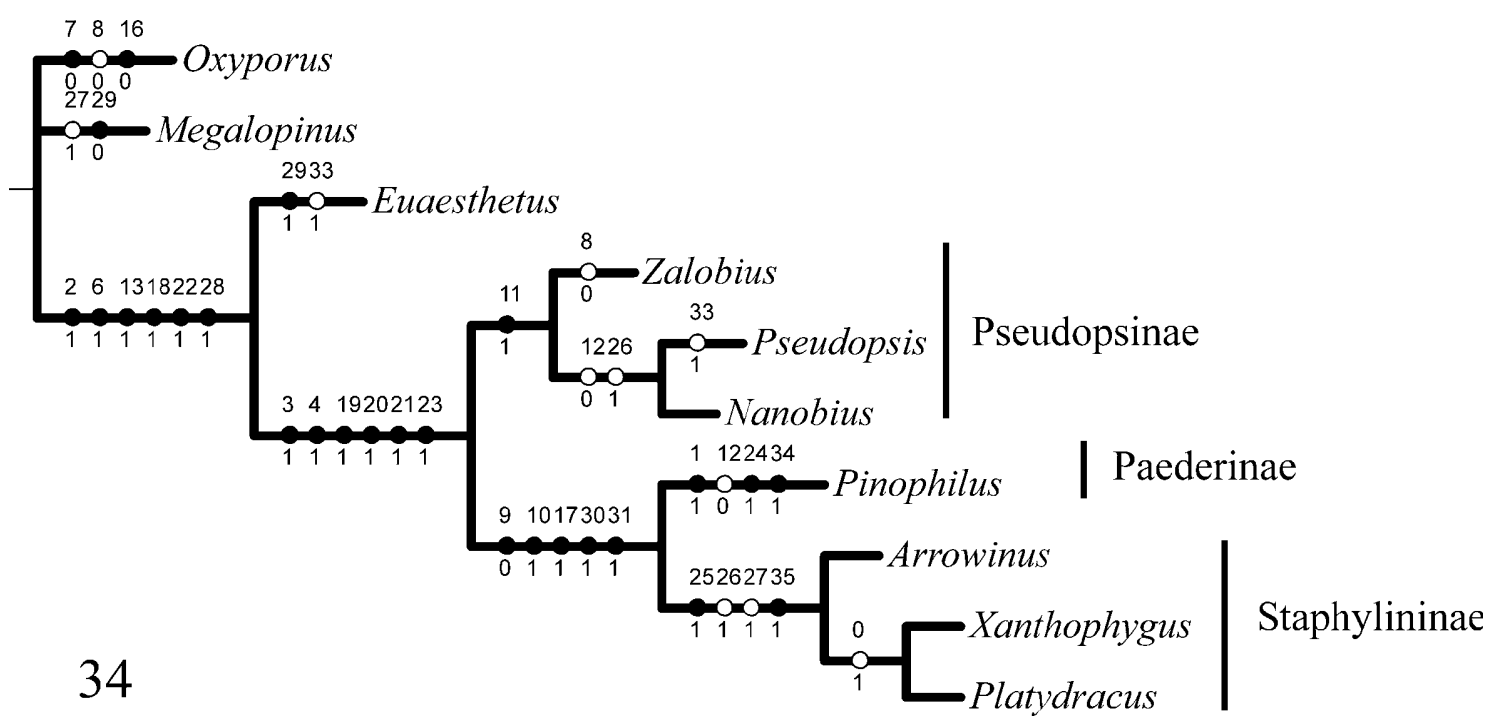

Fig. 34. Single most parsimonious tree representing hypothesized sister-group relationships of the subfamily Pseudopsinae to a clade comprising of the subfamilies Paederinae and Staphylininae. Tree length 43, ci 0.72, ri 0.80; characters 1, 7, 16, 24, 29, 34 and 35 are excluded from the analysis, but some of them are mapped on the tree. Only unambiguously optimized characters are shown. Black circles represent unique synapomorphies; white circles represent convergences or reversals.

2 Antennae 3-segmented (Figs 1, 3, 5); abdominal terga and sterna not divided mesally by membranous area (Figs 27-30); nuchal carina (if present) ventrally not transverse and directed meso-anteriorly (Figs 2, 4); ventral surface of head capsule with short, oblique and slightly curved ridge laterad of maxillary foramen (Figs $2,4,6) \ldots \ldots \ldots \ldots$. 4 (subfamily Pseudopsinae)

Antennae 4-segmented (with the basal antennomere being apparently subdivided by a membranous area into two subelements); abdominal terga and sterna characteristically divided mesally by membranous area; nuchal carina ventrally transverse; ventral surface of head capsule without short, oblique and slightly curved ridge laterad of maxillary foramina. . . . 3 (subfamilies Paederinae and Staphylininae)

3 Three pairs of trichobothria present on stipes, head capsule and pronotum; cervicosternum transverse, located anterior to proepisterna; ligula multisetose, not sclerotized. ....... ........................... Paederinae

- Trichobothria absent; cervicosternum triangular, apex projecting between proepisterna; ligula sclerotized, with at most one pair of setae on venter. . . . . . . . Staphylininae

4 Head capsule with frayed setae and without nuchal carina (Figs 5, 6); nasale with median tooth (Fig. 9); tergum of thorax with characteristic projections bearing setae (Figs 25, 26); tarsus with three small setae on each side at base of claw (Fig. 23); ventral ecdysial line Y-shaped with long anterior arms reaching anterior edge of head capsule (Fig. 6). Zalobius

Head capsule without frayed setae and with nuchal carina (Figs 1-4); nasale without median tooth (Figs 7-8); tergum of thorax without projections (Figs 19, 24); tarsus without three small setae on each side at base of claw (Figs 21-22); ventral ecdysial line ending with very short branches in vicinity of posterior tentorial pits and not reaching anterior edge of head capsule (Figs 2, 4) . . . . . . . . . . 5

5 Mala about as long as wide (Fig. 10); urogomphi 1-segmented, shorter than pygopod (Fig. 31)... . Pseudopsis

- Mala more than twice as long as wide (Fig. 12); urogomphi 2-segmented, longer than pygopod (Fig. 32).... . Nanobius

\section{Genus Pseudopsis Newman, 1834}

(Figs 1, 2, 7, 10, 11, 16, 19-21, 27, 28, 31)

Larval diagnosis: Head width: $0.43 \mathrm{~mm}(\mathrm{n}=2)$. Frayed setae on head, thorax and body absent (Figs 1, 2, 19, 20). Nuchal carina present (Figs 1-2); ventral ecdysial lines with short branches not extending anteriorly beyond posterior tentorial pits (Fig. 2); head capsule with rectangular microsculpture restricted to areas close to nuchal carina; apparently four closely amalgamated stemmata; median tooth on nasale absent, lateral teeth markedly developed (Fig. 7); mandibles not markedly elongated (Figs 1-2); mala short, about as long as wide (Fig. 10); ligula rather narrow, parallel-sided at base and tapered at apex (Fig. 11); without seta-bearing lateral projections of thoracic terga (Figs 19-20); posterior carina on prothorax present (Fig. 19); each side of tarsus near claw without three small short setae (Fig. 21); urogomphi shorter than pygopod, 1-segmented (Fig. 31); abdominal segment $\mathrm{X}$ short, about 2-3× longer than wide (Fig. 31 ).

Material. Pseudopsis montoraria Herman, 1975. Two apparently older instar larvae mounted on slides. Locality data: USA, Oregon, Curry Co., 12 mi north of Brookings, vicinity of Cape Ferrelo, April 2, 1983, litter, P. J. Johnson leg.

\section{Genus Nanobius Herman, 1977}

(Figs 3, 4, 8, 12, 13, 17, 22, 24, 32)

Larval diagnosis: Head width: $0.61 \mathrm{~mm}(\mathrm{n}=1)$. Frayed setae absent on head (Figs 3-4), partly present on thorax (Fig. 24) and abdomen, their characteristic apices only partly frayed and visible as frayed only under high magnification. Nuchal carina present (Figs 3-4); ventral ecdysial lines with short branches not extending anteriorly beyond posterior tentorial pits (Fig. 4); head capsule with rectangular microsculpture restricted to areas close to nuchal carina; six clearly separated stemmata; median tooth on nasale absent, lateral teeth poorly developed 

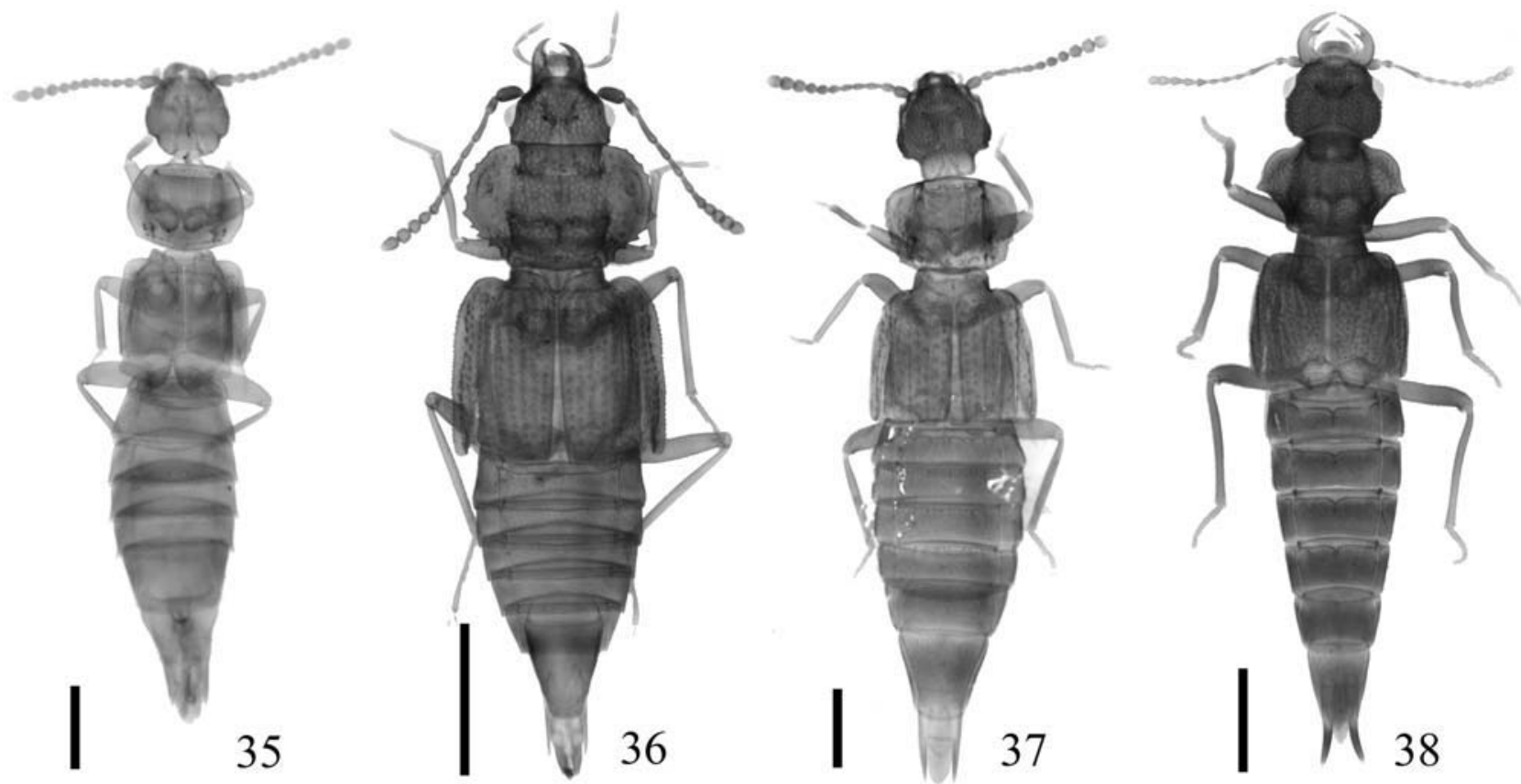

Figs 35-38. Adults of Pseudopsinae (Coleoptera: Staphylinidae), habitus, dorsal view. 35 - Pseudopsis montoraria; 36 - Asemobius caelatus Horn, 1895; 37 - Nanobius serricollis; 38 - Zalobius spinicollis. Scale bars: 35, 37 - 0.5 mm; 36, 38 - $1 \mathrm{~mm}$.

(Fig. 8); mandibles not markedly elongated (Figs 3-4); mala long, more than twice as long as wide (Fig. 12); ligula rather narrow, parallel-sided at base and tapered at apex (Fig. 13); without seta-bearing lateral projections of thoracic terga (Fig. 24); posterior carina on prothorax present (Fig. 24); each side of tarsus near claw without three small short setae (Fig. 22); urogomphi longer than pygopod, 2 -segmented, basal segment about $1.5 \times$ as long as apical (Fig. 32); abdominal segment $\mathrm{X}$ short, about 2-3× longer than wide (Fig. 32).

Material. Nanobius serricollis (LeConte, 1875). One apparently older instar larva mounted on slide. Locality data: USA, California, Los Angeles Co., Angeles Crest Highway, mile 49.06, $1635 \mathrm{~m}, 34^{\circ} 18^{\prime} 6^{\prime \prime} \mathrm{N}, 118^{\circ} 00^{\prime} 6^{\prime \prime} \mathrm{W}$, FMHD \#95-36, March 14, 1995, Quercus - Pinus coulteri - Pseudotsuga macrocarpa - Calocedrus decurrens, berlesing forest leaf and log litter, A. Newton and M. Thayer leg.

\section{Genus Zalobius LeConte, 1874}

(Figs 5, 6, 9, 14, 15, 18, 25, 26, 29, 30, 33)

Larval diagnosis: Head width: $0.90 \mathrm{~mm}$ (larger specimen); $0.50 \mathrm{~mm}$ (smaller specimen). Frayed setae present on head (Figs 5-6), thorax (Figs 25-26) and abdomen (Figs 29-30, 33), distinctly developed and easily visible. Nuchal carina absent (Figs 5-6); ventral ecdysial lines with long branches extending anteriorly beyond posterior tentorial pits and nearly reaching anterior edge of cranium (Fig. 6); head capsule with rectangular microsculpture covering most of its surface; six clearly separated stemmata; median tooth on nasale present, lateral teeth markedly developed (Fig. 9); mandibles markedly elongate (Figs 5-6); mala long, about twice as long as wide (Fog. 14); ligula rather wide, conical, setose (Fig. 15); with seta-bearing lateral projections of thoracic terga (Fig. 26); posterior carina on prothorax absent (Fig. 26); each side of tarsus near claw with three small short setae (Fig. 23); urogomphi longer than pygopod, 2-segmented, segments of equal length (Fig. 33); abdominal segment X long, about 4-6× longer than wide (Fig. 33).

Material: Zalobius spinicollis LeConte, 1874. Two apparently ultimate and penultimate instar larvae mounted on slides. Locality data: USA, California, Napa Co., $10.1 \mathrm{mi}$ north of Calistoga, 1900', May 21, 1976, from flood debris and along stream edge, A. Newton and M. Thayer leg.

\section{LIST OF MORPHOLOGICAL CHARACTERS USED IN THE ANALYSIS}

Characters were numbered in Nona/Hennig86 style (starting with the character 0 rather than 1). Many of the presently employed characters are not entirely new, but are those previously used by other authors. No attempt was made to trace all previous usages for such characters; in some cases, however, the most recent works employing these characters are cited. Some characters, which as far as I am aware have not been previously used, are indicated with appropriate remarks. Besides larval specimens, the following publications on Staphylinidae larval morphology were consulted when scoring characters: Frania (1986) and Leschen \& Newton (2003).

0. Frayed setae (Solodovnikov \& Newton, 2005, char. 99): absent (Fig. 1) $=0$; present (Fig. 5) $=1$.

Apically frayed setae are present in larvae of Zalobius and in some members of Staphylininae. In Nanobius setal morphology is somewhat intermediate between a typical frayed seta and a regular trichoid sensillum (coded as 1). Presence of frayed setae was noted for a number of the members of the family Staphylinidae (i.e. Thayer, 2005), thus indicating numerous independent evolutionary events in regard to this character.

1. Trichobothria (Kasule, 1966, Solodovnikov \& Newton, 2005, char. 100): absent $=0$; present $=1$. 
One pair of characteristic trichobothria is present on the stipes, each side of the head and each side of pronotum in larvae of Paederinae, which was commonly treated as an autapomorphy of the subfamily (Thayer, 2005). This character is uninformative. It was excluded from the analysis, but mapped on the MPT (Fig. 34).

2. Length of coronal suture (Beutel \& Molenda, 1997, char. 3, reworded): coronal suture shorter than half the length of head capsule $=0$; coronal suture as long as or longer than half the length of head capsule (Figs 1, 3, 5) $=1$.

The coronal suture is remarkably elongate in larvae of Euaesthetus and all ingroup taxa. This character state was optimized as a synapomorphy of these taxa on the MPT (Fig. 34).

3. The anteriorly directed sclerotized tooth of anterior part of ventral wall of head capsule on each side of the prementum articulating membrane: absent $=0$; present $($ Figs 2, 4, 6) $=1$.

A large anteriorly directed tooth of anterior part of ventral wall of head capsule originating on each side of the membrane, which connects prementum with the head capsule and is, apparently, homologous to the mentum and is present in larvae of all ingroup taxa. This character was optimized as their synapomorphy on the MPT (Fig. 34). This character was not previously used to justify the monophyly of this clade.

4. Constricted neck region (Solodovnikov \& Newton, 2005, char. 68, reworded): absent $=0$; present $($ Figs $1,3,5)=1$.

A markedly developed constricted neck region is present in larvae of all ingroup taxa. In Euaesthetus head capsule slightly narrowed posteriorly, but not so markedly as in ingroup and therefore it is scored as 0 . The character state 1 was optimized as an ingroup autapomorphy on the MPT (Fig. 34)

5. Dorsal ecdysial lines (Solodovnikov \& Newton, 2005, char 69, reworded): Y-shaped, anterior branches most widely separated at apex $=0$; lyriform, anterior branches most widely separated behind apex (Figs 1, 3, 5) $=1$.

The dorsal ecdysial lines are lyriform in larvae of all ingroup taxa. The character is ambiguously optimized on a tree due to the fact that a similar state is found in one of the outgroup taxa (Megalopinus). Potentially it might be an autapomorphy of the ingroup and an independently derived character in Megalopinus. It is equally parsimonious, however, to consider lyriform anterior branches as being only once acquired below on the tree and then secondarily lost in Euaesthetus.

6. Posterior tentorial pits (Solodovnikov \& Newton, 2005, char. 72): long, curved and forming distinct gular sutures $=0$; short, rounded to elongate (Figs 2, 4, 6) $=1$.

Posterior tentorial pints are short and rounded in all ingroup taxa plus Euaesthetus. This character state is optimized as a synapomorphy of these taxa on the MPT.

7. Posteriorly directed tentorial bridge: wide and short $=0$; extremely thin, thread-like and long $=1$.

The tentorial bridge is markedly thin and thread-like in larvae of all analyzed taxa, except Oxyporus. The character is uninformative, uniform in the ingroup and was excluded from the analysis.

8. Nuchal carina: absent $($ Figs 5,6$)=0$; present $($ Figs $1-4)=$ 1.

A markedly developed nuchal carina is present in larvae of all analyzed taxa, except Oxyporus and Zalobius (optimized as a reversal for the latter taxon)

9. Ventral part of nuchal carina: arms directed medially $=0$; arms directed antero-medially (Figs 2, 4) $=1$.

The ventral part of nuchal carina is directed medially in larvae of Paederinae and Staphylininae, which was optimized as a synapomorphy of these two subfamilies. This character was not previously used to justify the monophyly of this clade.
10. Ventral ecdysial lines (Solodovnikov \& Newton, 2005, char. 70, reworded): linear, extending from base of head to vicinity of posterior tentorial pits (Figs 2, 4) $=0$; Y-shaped, branching in vicinity of posterior tentorial pits and extending anteriorly between maxillary foramina $=1$.

The ventral ecdysial line in larvae of all Staphylininae and Paederinae taxa is Y-shaped with a characteristic apotome demarcated by the anterior divergent branches of the ventral ecdysial line and located between maxillary foramina. This character is shown to be a synapomorphy of Paederinae + Staphylininae (Solodovnikov \& Newton, 2005) and it was similarly optimized on the presently obtained MPT. It should be noted that in Pinophilus anterior branches are rather short and do not reach the anterior edge of head capsule (scored as 1). The state of this character is interpreted as 0 for Zalobius, in spite of the appearance of the ventral ecdysial line seemingly branching and anteriorly divergent from the level of posterior tentorial pits (Fig. 6). The reason for this decision is the fact that anterior branches in Zalobius pass outside of maxillary foramina (Fig. 6), while in Paederinae and Staphylininae larvae they pass between the foramina. These differences were considered as indicators of the non-homologous nature of both characters, with the character state of Zalobius being an autapomorphy of this genus.

11. Short oblique ridge on ventral side of head capsule near maxillary foramina: absent $=0$; present $($ Figs $2,4,6)=1$.

A short, slightly curved and oblique ridge near the maxillary openings of the cranium is present in larvae of all studied Pseudopsinae taxa. Such a structure was not found in other Staphylinidae larvae and this character is optimized as an autapomorphy of Pseudopsinae. This is the only discovered autapomorphy of the subfamily and it was not used previously.

12. Median tooth on nasale: absent (Figs 7,8 ) $=0$; present (Fig. 9) $=1$.

The median tooth of nasale is present in one member of the outgroup (Euaesthetus; the character is inapplicable for Oxyporus and Megalopinus) as well as in all Staphylininae and in Zalobius. Its absence was interpreted on the MPT as a parallel evolutionary novelty in Pseudopsis + Nanobius and in Paederinae.

13. Labrum (Beutel \& Molenda, 1997, char. 7, reworded): at least partly separated from clypeus $=0$; firmly fused to clypeus forming a nasale (Figs 1, 3, 5) $=1$.

Labrum is completely fused with clypeus forming a nasale in larvae of all ingroup taxa and those of Euaesthetus. This character is optimized as a synapomorphy of the above-mentioned taxa.

14. Main sensory appendage on antenna; its position with respect to articulation of apical segment (Solodovnikov \& Newton, 2005, char. 77): anterior (Figs 16-18) $=0$; ventral $=1$; dorsal $=2$.

Two members of the outgroup have state 0 , while the third member (Euaesthetus) has state 2. This character is ambiguously optimized on the MPT.

15. Shape of the main sensory appendage of antenna (Solodovnikov \& Newton, 2005, char. 78, reworded): bulbous, with convex sides and constricted base $=0$; very elongate and narrow, along much of its length parallel-sided (Figs 16-18) = 1.

A bulbous sensorial appendage is present in larvae of all outgroup and those of Staphylininae taxa. The character is optimized equally parsimoniously as an elongate shape being a synapomorphy for the ingroup and then a reversal to the bulbous shape for Staphylininae, or as two parallel gains of elongate shape in Pseudopsinae and Paederinae. 
16. Insertion of antennae on cranium (Beutel \& Molenda, 1997, char. 11): laterally $=0$; markedly shifted mesally (Figs 1 , $3,5)=1$.

Antennal insertion in larvae of all analyzed taxa, except $O x y$ porus, is shifted markedly mesally. This character is uninformative, uniform in the ingroup and was excluded from the analysis.

17. Antenna, number of antennomeres (Solodovnikov \& Newton, 2005, char. 76): three (Figs 1, 3, 5) $=0$; four $=1$.

Four segmented antenna (with the basal antennomere of plesiomorphic 3-segmented polyphagan antenna being separated by a membrane into two segments) is a characteristic feature and a synapomorphy of Paederinae and Staphylininae (Thayer, 2005).

18. Mandible, dentition (Solodovnikov \& Newton, 2005, char. 79): with 1-2 large pre-apical teeth $=0$; falcate, without teeth (Figs 1-6) $=1$.

Preapical mandibular teeth are lacking in larvae of all ingroup taxa and those of Euaesthetus, which is interpreted as a synapomorphy on the MPT (Fig. 34).

19. Mandible, serration: present $=0$; absent $($ Figs $1-6)=1$.

Mandibular serration is absent in larvae of all ingroup taxa and this character state was optimized as a synapomorphy. Some irregular microteeth in basal part of mandibles are present in larvae of Zalobius, which was, however, not interpreted as proper serration. It should be noted that larvae of some eight genera of Euaesthetinae (except Edaphus Motschulsky, 1857 and Euaesthetus), also lack any traces of mandibular serration (Grebennikov, unpublished). This indicates that the absence of the mandibular serration might equally parsimoniously be an apomorphy of a more inclusive clade (with a subsequent re-gain of the serration in Euaesthetus and Edaphus).

20. Ventral side of head (Solodovnikov \& Newton, 2005, char. 71): with free mentum and submentum, and anteriorly open maxillary foramen $=0$; with mentum and submentum fused to each other and to cranium posteriorly and completely closed maxillary foramen (Figs 2, 4, 6) $=1$.

The mentum and submentum are fused to each other and to cranium posteriorly, as well as the maxillary foramina are completely closed in larvae of all ingroup taxa. This complex character is interpreted as the most convincing autapomorphy of a clade containing Pseudopsinae, Paederinae and Staphylininae (Thayer, 2005).

21. Cardo: triangular or transverse, partly membranous, wider than long $=0$; elongate and completely sclerotized, longer than wide (Figs 2, 4, 6, 10, 12, 14) $=1$.

Elongate and completely sclerotized cardines are present in larvae of all ingroup taxa, which is interpreted as a synapomorphy. This character was not previously used to justify the monophyly of the ingroup.

22. Transverse ridge on cardo: present $=0$; absent (Figs 10, $12,14)=1$.

Larvae of all ingroup taxa and those of Euaesthetus lack a transverse sclerotized ridge on cardo, which is interpreted as a synapomorphy of these taxa. This character was not previously used to justify the monophyly of this group.

23. Mala (Solodovnikov \& Newton, 2005, char. 80, reworded): fused to stipes $=0$; articulated at base (Figs 10, 12, 14) $=1$.

A basally articulated mala is present in larvae of ingroup taxa, which is optimized as a synapomorphy on the MPT.

24. Ligula (Solodovnikov \& Newton, 2005, char. 83; reworded): sclerotized, with at most one pair of setae on ventral surface $=0$; not sclerotized, ventrally multisetose $=1$.

An unsclerotized and multisetose ligula is characteristic for Paederinae. This is an uninformative character. It was excluded from the analysis, but optimized as an autapomorphy of this subfamily on the MPT.
25. Cervicosternum (Solodovnikov \& Newton, 2005, char. 87): transverse, anterior to proepisterna (Figs 20, 25) $=0$; triangular, apex projecting between proepisterna $=1$.

A triangular cervicosternum with its apex projecting posteriorly between the proepisterna is characteristic for all Staphylininae larvae and was recently demonstrated to be an autapomorphy of this subfamily (Solodovnikov \& Newton, 2005).

26. Pronotum (Solodovnikov \& Newton, 2005, char. 84, reworded): without posterior carina $=0$; with posterior carina $=$ 1.

A transverse posterior carina is present on pronotum of Pseudopsis, Nanobius, and all analyzed taxa representing Staphylininae. This was interpreted as two independently gained synapomorphies on the MPT.

27. Meso- and metatergum (Solodovnikov \& Newton, 2005, char. 85 , reworded): without posterior carina $=0$; with posterior carina $=1$.

Posterior carina on meso- and metatergum is present in larvae of Staphylininae and those of Megalopinus, which was interpreted on the MPT as two independently gained autapomorphies.

28. Abdominal terga II-VIII (Solodovnikov \& Newton, 2005, char. 92): with anterior carinae $=0$; without anterior carinae $=1$.

Anterior carinae on abdominal terga II-VIII are present in larvae of all ingroup taxa and those of Euaesthetus, which was optimized as a synapomorphy on the MPT.

29. Abdominal laterosclerites (Solodovnikov \& Newton, 2005, char. 95; reworded): absent $=0$; one pair present $=1$; two pairs present on at least segments II-VI (Figs 28,30$)=2$.

Two pairs of laterotergites on abdominal segments II-VI are present in larvae of all ingroup taxa, while within the outgroup all three character states occur. This character is uninformative, uniform in the ingroup and was excluded from the analysis.

30. Abdominal terga (Solodovnikov \& Newton, 2005, char. 93, reworded): undivided (Figs 27, 29) $=0$; medially divided by membranous area on at least segments II-VIII $=1$.

Abdominal terga medially divided by a broad membrane is a characteristic feature of Paederinae and Staphylininae larvae, which is often considered as one of the synapomorphies of these two subfamilies (Thayer, 2005).

31. Abdominal sterna (Solodovnikov \& Newton, 2005, char. 94, reworded): undivided (Figs 28, 30) $=0$; medially divided on at least segments II-VIII $=1$.

Abdominal sterna medially divided by a broad membrane is a characteristic feature of Paederinae and Staphylininae larvae and was optimized as a synapomorphy on the MPT.

32. Abdominal terga II-VIII, urogomphi and pygopod; surface sculpture (Solodovnikov \& Newton, 2005, char. 96, reworded): surface smooth $=0$; with posteriorly directed microspines more or less randomly distributed $=1$; with posteriorly directed microspines in short curved rows $=2$.

The surface of sclerites is smooth in larvae of Megalopinus, Euaesthetus and Pinophilus; randomly distributed microspines are present in Oxyporus, Arrowinus and Pseudopsinae. The microsculpture consists of microspines arranged in short curved rows in two remaining Staphylininae genera Xanthopygus and Platydracus. This character is ambiguously optimized on the MPT.

33. Number of segments of urogomphi: two (Figs 32, 33) $=0$; one $($ Fig. 31$)=1$.

In contrast to the rest of the analyzed taxa, urogomphi are 1-segmented in larvae of Euaesthetus and Pseudopsis, which were optimized as two independent autapomorphies on the MPT.

34. Number of larval instars: three $=0$; two $=1$. 
All larvae of Paederinae have only two larval instars, as far as it is known at present (Thayer, 2005), which is considered to be an autapomorphy of this subfamily. The character state for Pseudopsinae is unknown. The character is excluded from the analysis but was tentatively mapped as an autapomorphy of Paederinae on the MPT.

35. Pupae: exarate $=0$; obtect $=1$.

The subfamily Staphylininae is characterized by having obtect pupae (Thayer, 2005), which is considered to be an autapomorphy of this subfamily. The character state for Pseudopsinae is unknown. The character was excluded from the analysis, but was tentatively mapped as a Staphylininae autapomorphy on the MPT.

\section{DISCUSSION}

\section{The subfamily Pseudopsinae}

The monophyly of the subfamily Pseudopsinae, which was corroborated by a number of morphological characters of adults (Newton, 1982), is also supported by the present analysis of larval morphology. A single unique character, namely the presence of the short oblique ridge on the ventral wall of the head capsule laterally of the maxillary foramen $(11 / 1$; Figs $2,4,6)$, was optimized as an autapomorphy of the subfamily on the most parsimonious tree (Fig. 34). This characteristic structure is unknown in other analyzed larvae of Staphylinidae and is assumed to be an evolutionary novelty of Pseudopsinae. Besides this, no further evidence from larval morphology is currently available to support or challenge the monophyletic origin of the subfamily.

It should be mentioned that the short ventral oblique ridges found in Pseudopsinae (Figs 2, 4, 6) and assumed to be newly evolved structures might, in fact, represent remnants of the ventral epicranial ridges widely distributed within Coleoptera larvae (Lawrence et al., 1999). The ventral epicranial ridges are fully obliterated in Staphylininae and Paederinae larvae as a result of the fusion of the base of the maxillary-labial complex to the head capsule. If this is correct, then the short ventral oblique ridges rather than being an evolutionary novelty and an autapomorphy for Pseudopsinae, must be considered as homologous to, and an intermediate stage of reduction of, the ventral epicranial ridges, and thus plesiomorphic within a clade containing Pseudopsinae, Paederinae and Staphylininae. If correct, this hypothesis will leave the subfamily Pseudopsinae without larval apomorphies.

The phylogenetic relationships among the four genera of Pseudopsinae were hypothesized by Newton (1982) as following: Pseudopsis + [Nanobius + (Asemobius + Zalobius)]. In the present paper no attempt was made at addressing the interrelationships within the subfamily, because of the limited set of available taxa. It seems, however, worth noting some remarkable and likely apomorphic larval characters of Pseudopsis (1-segmented urogomphi; short mala) and Zalobius (numerous frayed setae; absence of nuchal carina; peculiarly branching anteriorly divergent ridges originating from posterior tentorial pits and passing antero-laterally outside of maxillary foramina, see also discussion under character 10; tarsus with three small setae on each side near claw), which might be of further interest.

\section{The subfamily Staphylininae}

The monophyly of the subfamily Staphylininae (s. lato, including Xantholininae) is well established based on both larval and adult morphological characters (Solodovnikov \& Newton, 2005). The following larval synapomorphies of its members were previously cited (Solodovnikov \& Newton, 2005): protibial comb present (not included into the present analysis) and cervicosternum of triangular shape with its apex projecting between proepisterna (25/1). The obtect pupa (Thayer, 2005) was also indicated as a possible autapomorphy of the subfamily and was mapped tentatively as such on the MPT (35/1; data on pupae of many Staphylininae taxa are missing). Two more characters, both explored previously by Solodovnikov \& Newton (2005) turned out as possible autapomorphies of Staphylininae in the present analysis: tergum of prothorax with posterior carina (26/1) and terga of meso- and metathorax with posterior carina (27/1).

\section{The subfamily Paederinae}

Like that of Staphylininae, the monophyly of Paederinae was well established by previous authors (see Thayer, 2005) and its corroboration was not within the scope of the present work. Solodovnikov \& Newton (2005) cited the following larval synapomorphies of its members: characteristic trichobothria present on stipes, head capsule and pronotum (1/1); ligula unsclerotized and ventrally multisetose $(24 / 1)$; and main sensory appendage on antenna located dorsally (14/2; ambiguously optimized on the MPT; shown as an autapomorphy of Paederinae only with DELTRAN optimization). The absence of the medial tooth of the nasale is presently shown as a possible autapomorphy of the subfamily (12/0; derived independently in some Pseudopsinae larvae). Additionally, the larval development with only two instars (34/1) was indicated by Thayer (2005) as a possible autapomorphy of Paederinae and was mapped as such on the MPT.

It should be noted, that a few members of the subfamily are reported to have the main sensory appendage on antenna located anterior and posterior rather than dorsal (Newton, 1990; Thayer, 2005). Since the relationships within Paederiane are currently unresolved, it is not therefore excluded, that the dorsal position of the main antennal sensorium is not an autapomorphy of the subfamily, but rather one arising from within it.

\section{Monophyly of Paederinae + Staphylininae}

Solodovnikov \& Newton (2005), as a result of their combined larval and adult characters, cited three larval synapomorphies to link the subfamilies Paederinae and Staphylininae. They are all recognized as such by the present analysis: ventral ecdysial line anteriorly Y-shaped (10/1), antennae 4-segmented (17/1), and abdominal sterna II-VIII divided mesally by membranous area (31/1). Two additional putative larval synapomorphies are found here: ventral arms of nuchal carina directed medially (9/0); and abdominal terga II-VIII divided mesally 
by membranous area (30/1). The last character was previously mentioned (Thayer, 2005) and analysed phylogenetically (Solodovnikov \& Newton, 2005), but was not optimized as an apomorphy on their MPT (Solodovnikov \& Newton, 2005).

\section{Monophyly of Pseudopsinae + (Paederinae + Staphylininae)}

The monophyly of the clade comprising the subfamilies Pseudopsinae, Paederinae and Staphylininae is supported with the following six unambiguously optimized unique autapomorphies: presence of a characteristic anteriorly directed tooth on each side of labial attachment to head capsule (3/1); neck region distinctly constricted (4/1); mandibles without serration (19/1); ventral side of head capsule with mentum and submentum fused to each other and to head capsule posteriorly and maxillary foramen completely closed (20/1); cardo elongate and completely sclerotized, longer than wide (21/1), mala articulated at base (23/1). Moreover, the use of ACCTRAN optimization offers three more possible apomorphies: dorsal ecdysial lines more or less lyriform, anterior branches most widely separated behind apex (5/1; also in Megalopinus); main sensory appendage on antenna very elongate and narrow, parallel-sided along much of its length (15/1; reversal in Staphylininae); and abdominal terga II-VIII, urogomphi and pygopod with posteriorly directed microspines present (32/1; also in Oxyporus, reversal in Paederinae and further transformation in Xanthopygus and Platydracus into 32/2).

ACKNOWLEDGEMENTS. This work is almost exclusively based on the larvae borrowed from the collection of Staphylinoidea stored at the Field Museum of Natural History (Chicago, USA). The curators, A.F. Newton and M.K. Thayer, are acknowledged for the permission to access the collection. The project was funded by the Research Fellowship from the Alexander von Humboldt Foundation (www.avh.de; Bonn, Germany) and mainly carried out at Friedrich-SchillerUniversität Jena (Germany). The first draft of the manuscript was critically read by R.G. Beutel, my research host at this institution.

\section{REFERENCES}

Beutel R.G. \& Molenda R. 1997: Comparative morphological study of larvae of Staphylinoidea (Coleoptera: Polyphaga) with phylogenetic implications. Zool. Anz. 236: 37-67.

FARRIS J.S. 1988: Hennig86, version 1.5. Published by the author, Port Jefferson Station, New York.

Frania H.E. 1986: Larvae of Eustilicus Sharp, Rugilus Leach, Deroderus Sharp, Stilocharis Sharp and Medon Stephens (Coleoptera: Staphylinidae: Paederinae) and their phylogenetic significance. Can. J. Zool. 64: 2543-2557.
Hadley A. 2004: CombineZ, version 4. Published by the author. Available from URL: $<$ http://www.hadleyweb.pwp.blueyonder.co.uk/index.htm $>$ Accessed/Downloaded December 4, 2004.

HERMAN L.H. 1975: Revision and phylogeny of the monogeneric subfamily Pseudopsinae for the world (Coleoptera: Staphylinidae: Piestinae). Bull. Am. Mus. Nat. Hist. 155: 241-318.

HERMAN L.H. 1977: Revision and phylogeny of Zalobius, Asemobius and Nanobius, new genus (Coleoptera: Staphylinidae: Piestinae). Bull. Am. Mus. Nat. Hist. 159: 45-86.

Herman L.H. 2001: Catalog of the Staphylinidae (Insecta: Coleoptera). 1758 to the end of the second millennium. IV. Staphylinine Group (Part 1): Euaesthetinae, Leptotyphlinae, Megalopsidiinae, Oxyporinae, Pseudopsinae, Solieriinae, Steninae. Bull. Am. Mus. Nat. Hist. 265: i-v, 1807-2439.

Kasule F.K. 1970: The larvae of Paederinae and Staphylininae (Coleoptera: Staphylinidae) with keys to the known British genera. Trans. R. Entomol. Soc. Lond. 122: 49-80.

LaWrence J.F. 1991: Order Coleoptera (general discussion, family key, various family treatments). In Stehr F.W. (ed.): Immature Insects. Vol. 2. Kendall/Hunt, Dubuque, Iowa, pp. $144-658$.

Lawrence J.F., Hastings A.M., Dallwitz M.J., Paine T.A. \& ZuRCHER E.J. 1999: Beetle Larvae of the World: Descriptions, Illustrations, Identification, and Information Retrieval for Families and Sub-families. CD-ROM, Version 1.1 for MSWindows. CSIRO Publishing, Melbourne.

LESCHEN R.A.B. \& Newton A.F. 2003: Larval description, adult feeding behavior, and phylogenetic placement of Megalopinus (Coleoptera: Staphylinidae). Coleopt. Bull. 57: 469-493.

Nixon K.C. 2002: WinClada version 1.00.08. Published by the author, Ithaca, NY.

Newton A.F. 1982: Re-definition, revised phylogeny and relationships of Pseudopsinae (Coleoptera: Staphylinidae). Am. Mus. Nov. 2743: 1-13.

Newton A.F. 1990: Insecta: Coleoptera: Staphylinidae, adults and larvae. In Dindal D.L (ed.): Soil Biology Guide. Jonh Wiley and Sons, New York, pp 1137-1174.

Newton A. F. \& Thayer M.K. 2003: Catalog of higher taxa of Staphyliniformia and genera and subgenera of Staphylinoidea [online]. Chicago: Field Museum of Natural History [last updated on October 14, 2003]. Available from URL: $<$ http://www.fieldmuseum.org/peet_staph/db_1a.html > Accessed/Downloaded October 4, 2004.

Solodovnikov A.Yu. \& Newton A.F. 2005: Revision of the relict South African genus Arrowinus, description of its larva, and phylogenetic assessment of Arrowinini trib. n. (Coleoptera: Staphylinidae: Staphylininae). System. Entomol. 30: 398-441.

THAYER M.K. 2005: 11. Staphylinoidea. 11.7. Staphylinidae In: Coleoptera, Vol. I. Morphology and Systematics (Archostemata, Adephaga, Myxophaga, Polyphaga partim). In Beutel R.G. \& Leschen R.A.B. (eds): Handbook of Zoology Vol. IV. Arthropoda: Insecta. De Gruyter, Berlin, New York.

Received November 9, 2004; revised and accepted April 8, 2005 